\title{
Dallas Ice Corporation And Its Premium Beverage Ice Product ${ }^{1}$
}

Alma Mintu-Wimsatt, (Email: alma_wimsatt@tamu-commerce.edu), Texas A \& M University - Commerce Mary Anne Milward, (Email: mamilward@aol.com), Texas A \& M University - Commerce

\section{DALLAS ICE CORPORATION AND ITS PREMIUM BEVERAGE ICE PRODUCT}

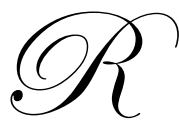

obert Payne has often pondered on the incredible success of bottled water - who would have thought selling water could be very profitable! The array of brands available on store shelves is a testament to bottled water's success. In fact, according to the Beverage Marketing Corporation, sales of bottled water in the United States rose $9.3 \%$ in 2000 reaching the $\$ 5.7$ billion mark. A report generated by the 2001 U.S. Drinking Water Segments has identified that consumers' concerns relating to health, fitness, and quality are among the driving forces to bottled water's popularity.

\section{ICE IS ICE - OR IS IT REALLY?}

Because of the success of bottled water, Robert Payne and his business partner, Darren Bear, have wondered on how bottled water's success can carry over to the packaged ice business. Their preliminary research showed that $20 \%$ of packaged ice is directly purchased for consumption. The other $80 \%$ is used for refrigeration, such as cooling soft drinks, beer and water.

Payne and Bear, who own and distribute ice in the Dallas-Fort Worth area, have questioned if consumers would be receptive to the notion of purchasing ice products made from bottled water? And if they are interested in bottled water quality ice, what would be the most effective means of marketing this "premium" beverage ice product? Most importantly, what types of consumers would most likely purchase "premium" beverage ice?

\section{SOME INDUSTRY INFORMATION}

Packaged ice industry represents approximately $\$ 1.0$ billion to $\$ 1.5$ billion at retail. It is dominated by small companies who service a single market or local region. The growth of packaged ice industry resulted from the growth of convenience stores, evolution of the ice industry and the introduction of a designated cold cabinet ice merchandiser (www.refrigeration-magazine.com).

DIC is currently one of the dominant companies servicing the Dallas-Fort Worth area. Reddy Ice is the only national company that has a strong base in Dallas. DIC ranks among top three local ice manufacturers in the region. This is because DIC has been in business for several decades in the Dallas-Fort Worth area. The company used to be owned by Payne's father, back during the days when homes did not have refrigeration units and buying blocks of ice was the norm.

\section{COMPANY BACKGROUND}

Dallas Ice Corporation (DIC) is a Dallas-based icemaker that distributes ice products in the Northeast Texas region. DIC manufactures ice products for both business and household purposes. Among its business accounts, Dallas Ice has existing contracts with major sports centers and teams in Dallas. As for household

\footnotetext{
1 This case is based on an actual case. Names have been disguised at the request of the owners. Facts in this case have been printed with permission from the owners.
} 
products, the most popular form of ice product the company sells is the 8-10 lb. bag of ice found in most convenient stores and supermarkets.

Today, DIC's ice making business has successfully evolved with the changes in the market place. The company prides itself with its technological competence in manufacturing ice products and is highly regarded by other ice manufacturers around the country. As far as the industry is concerned, Payne is well-respected by his peers, serving as an officer of the International Packaged Ice Association and the Southwestern Ice Association.

\section{INFORMATION ON THE 4 P'S}

Upon looking into the success of bottled water, Payne and Bear came up with the idea of manufacturing a different type of ice - a premium beverage ice product - making ice using bottled water. They contend that if consumers prefer bottled water because of health and sanitation concerns, they should also be concerned with the water that goes into their ice cubes. That is, using regular store bought ice for beverage use is just like using tap water. Why would anyone want to use tap water ice with their beverage, not to mention their cocktail drinks?

Just as alarming, the ice cubes generated from consumers' freezer units are actually unsanitary given its use of tap water and the cubes' exposure to other elements when left uncovered in the freezer. Typically for most households, ice cubes are left unwrapped or exposed in the icemaker container. In fact, even those using filter systems with their refrigeration units still do not have bottled water quality.

In 2001, DIC developed a premium beverage ice product. This new product is a one-inch smooth cube ice made from Reverse Osmosis (popularly known as RO) water with Ultra Violet and Carbon filtration. This is the same process employed by companies that sell bottled water. The National Sanitation Foundation (NSF) and the Packaged Ice Quality Control Standard (PIQCS) certify the process used by DIC to manufacture the premium beverage ice.

Premium Ice ${ }^{2}$ will be packaged differently from the generic 8-10 pound ice packages currently seen in the marketplace. It will be placed in a resealable zipper-lock package in four-pound units. While Premium Ice will be sold in smaller packages, the product will cost more. Suggested retail price to the end user will be $\$ 1.89$ plus tax. Premium Ice will demand higher pricing due to the extensive manufacturing process and will be sold in smaller quantities because of the shelf space in home freezer.

Initial market entry will be limited to the Dallas-Fort Worth area. Payne and Bear anticipate that they will use its current distribution networks comprised of supermarkets, convenient stores, grocery stores and some specialty outlets (e.g., whole foods stores). On one hand, they hope that using the distribution network already in existence [with their other consumer ice products] will facilitate the introduction of a new ice product in the market place. On the other hand, Payne and Bear are second-guessing if the distribution of Premium Ice should actually be patterned after that of regular ice.

\section{POINTS TO PONDER}

Payne and Bear believe that they have a truly innovative product. Initial market research indicates that their product has good potential (i.e., consumers see the need for the product). More importantly, the profit margin for the product is relatively promising.

Unfortunately, Payne and Bear are not sure how much consumers are actually willing to pay to their product. Should they test market the product first? If they do, it is noteworthy to remember that the Reserve Osmosis technology used to manufacture their product cannot be patented. Therefore, any of their competitors can easily launch a similar product.

\footnotetext{
2 "Premium Ice" is the generic brand name used for the purposes of this case.
} 
While they want to pioneer market entry in the Dallas-Fort Worth area, Payne and Bear also recognize that being the first to introduce the product does not necessarily mean immediate success. Therefore, they want a solid marketing strategy for Premium Ice's introduction in the Dallas Fort-Worth area. In devising this strategy, several questions seem to perpetually pop up. Who should be the target market? What is the most effective way to reach this target? Is the price of $\$ 1.89$ for a 4-lb bag too much? What should their marketing strategy include?

\section{REFERENCES}

1. “Taste Pivotal to Water Growth,” Supermarket News, November 12, 2001.

2. Bottled Water Web (www.bottledwaterweb.com).

3. www.refrigeration-magazine.com.

\section{CASE OBJECTIVES AND USE:}

\section{Dallas Ice Corporation and its Premium Beverage Ice Product}

\section{Intended Courses:}

Senior-level marketing strategy course

Graduate-level marketing management course

\section{Objectives:}

This case was developed to provide students with an understanding and application of:

1) The role of the marketing function in an organization;

2) The process involved in understanding consumers and target marketing;

3) The importance of coordinating the different elements of the marketing mix;

4) The concepts relating to product differentiation, position and competitive advantage;

5) To integrate the concepts learned in the marketing course; and,

6) To effectively produce and present a successful marketing strategy.

\section{Audience:}

This case is appropriate for senior marketing and graduate marketing and/or business students. At these levels, students have been sufficiently exposed to various marketing concepts and should be able to effectively integrate these concepts together. More importantly, this case provides a good foundation for the elements involved in the planning of an effective marketing strategy.

\section{CASE SYNOPSIS:}

\section{Dallas Ice Corporation and its Premium Beverage Ice Product}

Dallas Ice Corporation is a Dallas-based ice maker and distributor headed by Robert Payne and Darren Bear. The company sells household and business ice products in the Northeast Texas region. As in most ice companies, the most popular form of household ice product it sells is the 8-10 lb. bag of ice found in most convenient stores and supermarkets. Depending on the retail outlet, these bags of ice are sold at a price range of $\$ .99$ to $\$ 1.50$. 
DIC intends to introduce a new form of ice product - a beverage ice product. The primary consumer benefit in buying this new product is the fact that it uses "bottled water." This new product is a one-inch smooth cube ice made from Reverse Osmosis water with Ultra Violet and Carbon filtration. Therefore, this ice product will be sold primarily as "table ice" or "beverage ice."

Initial market entry will be limited to the Dallas-Forth Worth area. Known in its generic form as Premium Ice, the product will be priced higher than the regular ice product (suggested retail price is $\$ 1.89$ plus tax). Premium Ice will be packaged in four pound resealable zipper bags. Payne and Bear anticipate using DIC's current network of supermarkets, grocery, convenience and some specialty stores for distribution.

\section{DISCUSSION QUESTIONS AND ANSWERS:}

\section{Dallas Ice Corporation and its Premium Beverage Ice Product}

1) Based on the information provided, outline the elements of the marketing mix

Product: Premium Ice

Price: $\quad \$ 1.89$ plus tax

Place: $\quad$ Current network of supermarkets, grocery stores \& convenience stores

Promotion: To be determined by class

2) Identify the selling points of Premium Ice?

The key benefits of buying Premium Ice are health and sanitation related. However, a secondary benefit may be derived from its smooth shape. It may have better cosmetic appeal when served in social settings.

3) For the purposes of this case, the product was simply called "Premium Ice." Suggest appealing brand names that DIC could use.

In suggesting potential brand names, names that conjure images of Premium Ice's benefits ought to be highlighted.

Currently, the company is in the process of applying for a trademark on the brand name "Blu."

4) Should Payne and Bear test the market first? Identify advantages and disadvantages of test marketing?

5) Apply the process of segmentation and provide a profile of the consumer most likely to purchase this product.
a. Upper income, upper class neighborhoods
b. $\quad$ Health conscious - those that work out on a regular basis
c. Patrons of specialty stores such a whole foods grocery stores
d. Those who entertain in their homes on a regular basis
e. Special occasion use - such as picnics and social functions

6) How can we reach the consumer described in question \#5?

a. $\quad$ Selective upper class target magazines such as the D Magazine for the Dallas-Fort Worth area. Those not familiar with Dallas are encouraged to use a sample city that typifies the cosmopolitan nature of Dallas.

b. Whole Foods grocery stores 
c. Provide complimentary services with bottled water delivery

d. Based on geographic segmentation (i.e., certain upscale neighborhoods) - provide freezers in selected supermarkets

7) Evaluate the following elements of the marketing mix.
a. The use of the resealable package;
b. $\quad$ Pricing of $\$ 1.89$ plus tax for a four-pound bag;
c. Use of convenience stores as part of the distribution network.

The key to the success of Premium Ice is to regard the product as a truly premium product similar to the introduction of premium ice cream. Therefore, DIC has to be selective in its choice of exposure and distribution. Gasoline station stores or convenience stores may not be feasible alternatives.

While the product may be considered pricey, we need to know how many servings are in a 4-lb bag. This information will be critical in using this product as beverage ice.

8) Suggest some effective ways to introduce the product in the Dallas Fort Worth area.
a. $\quad$ Give samples in supermarkets
b. Sponsor prominent social functions
c. Introduce free bags with bottled water delivery service
d. Sponsor some family-oriented sports events

9) Recommend a strategy for premium ice.

Key points of this strategy should highlight the consumers' habits and characteristics as well as the health and sanitation benefits derived from the product. Premium ice is NOT for everyone who buys packaged ice. Instead, it is for a small segment of ice buyers - much like those who purchase premium ice cream products (such as Godiva Ice Cream).

10) Do you anticipate competition to follow immediately?

Competitors will most likely follow if Premium Ice becomes a successful product. Since Reverse Osmosis is a process available to any ice manufacturer - there are low barriers to entry. Therefore, entry of competitors should be anticipated. 
Notes 